\title{
Editorial
}

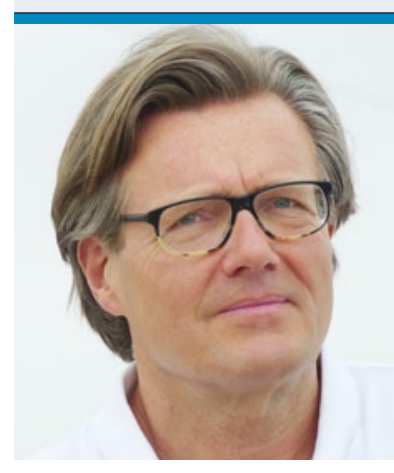

Wir freuen uns, wenn Sie die redaktionelle Arbeit auch weiterhin

mit Fragen, Anregungen und Kritik unterstützen.

Prof. Dr. med. Gerhard Grevers

Chefredaktion

\section{Gewappnet für künftige Herausforderungen}

eser der kurzweiligen und häufig zum Schmunzeln anregenden Editorials der vergangenen Jahre werden an dieser Stelle das Foto von Dieter Leithäuser vermissen, der die "Startseite“ der HNO-Nachrichten lange Zeit durch seine Beiträge geprägt hat und dessen Nachfolge ich mit dem vorliegenden Heft übernommen habe.

Mehr als 10 Jahre im Beirat der Zeitschrift boten mir reichlich Gelegenheit, deren Entwicklung in einer Phase mit zu verfolgen und zu gestalten, in der der zunehmende Einfluss digitaler Medien auch zu umfangreichen Veränderungen im Bereich der medizinischen Fortbildung führte.

Das Konzept, praktisch relevante HNO-Heilkunde auf aktuellem, wissenschaftlich fundiertem Niveau zu vermitteln, das Redaktion, Beirat und Verlag seit Jahren kontinuierlich verfolgen, scheint bei der Leserschaft weitgehend auf Akzeptanz zu stoßen; so zeigen es die Zahlen. Dieter Leithäuser hat hier in den vergangenen 13 Jahren als Chefredakteur hervorragende Arbeit geleistet. Insofern wird sich an der Heftgestaltung zunächst einmal auch nichts ändern.

Dennoch, in Zeiten zunehmender Internetpräsenz auch im medizinischen Bereich, stehen die Printmedien - in vielen Bereichen in die Defensive gedrängt - ständig neuen Herausforderungen gegenüber, denen es sich zu stellen gilt.
Als Dienstleister in der medizinischen Fortbildung suchen wir auch deshalb den Dialog mit Ihnen; nur in der konstruktiven Interaktion zwischen Leserschaft und Redaktion lässt sich dauerhaft eine Zeitschrift realisieren, die für Sie als HNO-Ärzte von Interesse ist.

In diesem Sinne würde ich mich freuen, wenn Sie unsere Arbeit auch weiterhin durch Fragen, Themenvorschläge und Kritik jedweder Art unterstützen, damit die HNO-Nachrichten auch in Zukunft ihrer Aufgabe als Fortbildungsorgan für Praxis und Klinik gerecht werden kann.

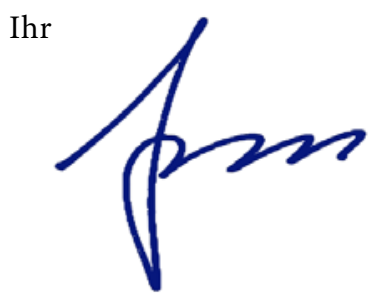

